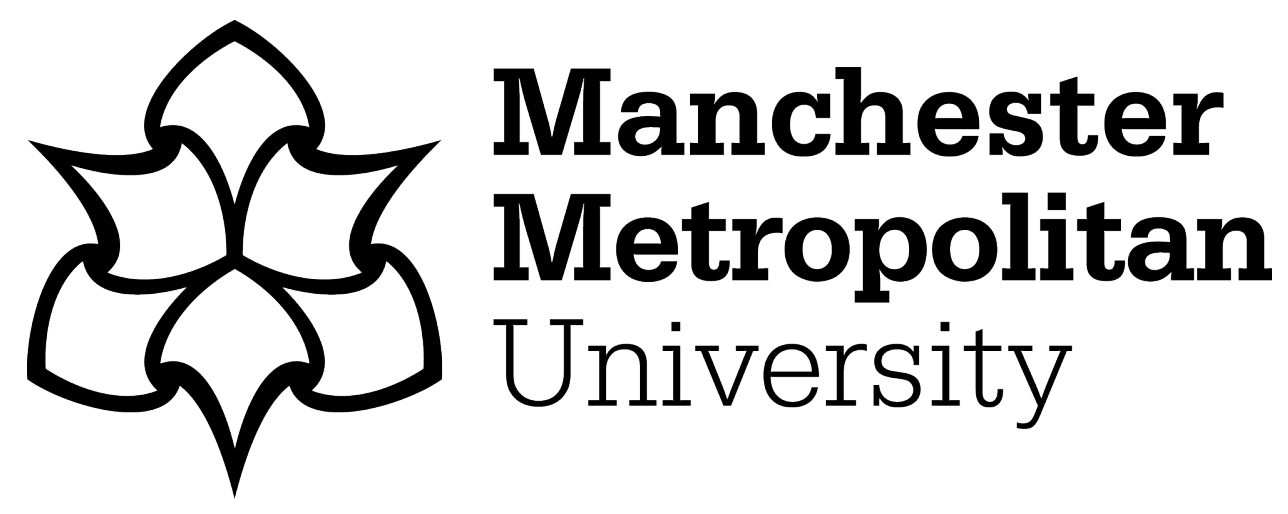

King, LA ORCID logoORCID: https://orcid.org/0000-0002-0772-2378, Hellstern, TR, Park, J, Sinclair, R and Jaramillo, TF (2017) Highly Stable Molybdenum Disulfide Protected Silicon Photocathodes for Photoelectrochemical Water Splitting. ACS Applied Materials and Interfaces, 9 (42). pp. 3679236798. ISSN 1944-8244

Downloaded from: https://e-space.mmu.ac.uk/624300/

Version: Accepted Version

Publisher: American Chemical Society (ACS)

DOI: https://doi.org/10.1021/acsami.7b10749

Please cite the published version 


\title{
Highly Stable Molybdenum Disulfide Protected Silicon Photocathodes for Photoelectrochemical Water Splitting
}

Laurie A. King, ${ }^{1}$ Thomas R. Hellstern, ${ }^{1}$ Joonsuk Park, ${ }^{2}$ Robert Sinclair ${ }^{2}$ and Thomas F. Jaramillo $^{1 *}$

${ }^{1}$ Department of Chemical Engineering, Shriram Center, Stanford University, 443 Via Ortega, Stanford, California 94305, United States

${ }^{2}$ Department of Materials Science and Engineering, Stanford University, 496 Lomita Mall, Stanford, California 94305

\begin{abstract}
Developing materials, interfaces and devices with improved stability remains one of the key challenges in the field of photoelectrochemical water splitting. As a barrier to corrosion, molybdenum disulfide is a particularly attractive protection layer for photocathodes due to its inherent stability in acid, the low permeability of its basal planes, and the excellent hydrogen evolution reaction (HER) activity the $\mathrm{MoS}_{2}$ edge. Here, we demonstrate a stable silicon photocathode containing a protecting layer consisting of molybdenum disulfide, molybdenum silicide, and silicon oxide which operates continuously for two months. We make comparisons between this system and another molybdenum sulfide - silicon photocathode embodiment, taking both systems to catastrophic failure during photoelectrochemical stability measurements and exploring mechanisms of degradation. X-ray photoelectron spectroscopy and transmission electron microscopy provide key insights into the origins of stability.
\end{abstract}




\section{Introduction}

Hydrogen is an important industrial chemical for ammonia synthesis and petroleum refining with annual production of over 65 million tons. ${ }^{1}$ Sustainably produced hydrogen also offers a renewable alternative to fossil fuel based energy as an energy carrier for the transportation sector. Currently, $96 \%$ of our hydrogen is produced from fossil fuels (mostly by steam methane reformation of natural gas) with $\mathrm{CO}_{2}$ as a by-product. Photoelectrochemical (PEC) water splitting is an attractive and promising alternative route for the conversion of sunlight into hydrogen without direct production of $\mathrm{CO}_{2} \cdot{ }^{2}$ However, for PEC to become economically viable, the efficiency and durability of electrodes must be improved. ${ }^{3}$

Silicon is a promising candidate material for use in PEC water splitting systems due to its excellent electronic properties, appropriate band gap of $1.1 \mathrm{eV}$, which is suitable for the small band gap electrode in a dual absorber device, and band alignment to drive the hydrogen evolution reaction (HER). ${ }^{4}$ However, bare silicon surfaces exhibit slow kinetics for hydrogen evolution and corrode readily in aqueous electrolytes, necessitating the use of strategies which speed the HER and slow corrosion. To date, several methods have been employed to stabilize semiconductor surfaces against corrosion including, thin film protection layers which can also enhance HER catalysis, ${ }^{5}$ the replacement of aqueous electrolyte with non-corrosive nonaqueous redox systems, ${ }^{6,7}$ and surface functionalization with organic molecules that prevent corrosion $^{8}$. The simplest and most effective strategy to date is the use of conductive and electrochemically stable thin films that act as a physical barrier to corrosion. ${ }^{5}$ Numerous protecting and catalytically active materials have been employed with varying degrees of success including $\mathrm{Pt},{ }^{9}$ metal oxides, ${ }^{10-12}$ phosphides, ${ }^{13,14}$ sulfides, ${ }^{15,16}$ and silicides ${ }^{9}$.

One such material that has shown excellent stability as a protection layer for PEC water splitting photocathodes is molybdenum disulfide $\left(\mathrm{MoS}_{2}\right)$. MoS 2 is known for its exceptional stability, HER activity in acid, and its low permeability, making it an excellent candidate as a protective catalyst for PEC applications. ${ }^{17}$ Indeed, $\mathrm{MoS}_{2}$ protection layers have been utilized to extend the durability of gallium indium phosphide photocathodes for over $60 \mathrm{hrs}^{18}$ and silicon photocathodes for over 100 hours. ${ }^{15,16}$

Metal silicides, which are typically formed by sputtering a metal directly onto silicon, are also interesting candidates for protection layers on silicon due to their inherent stabilities, ${ }^{19}$ and the excellent interface between the silicon absorber and silicide layer. Silicides of platinum, for instance, have been investigated as protection layers for water splitting photoelectrodes 
with excellent results; specifically, sputtered platinum silicide thin films show stable activity under continuous operation for 58 days (a total of $20000 \mathrm{C} . \mathrm{cm}^{-2}$ was passed) in $1 \mathrm{M}$ hydrochloric acid. ${ }^{9}$ There have also been reports utilizing platinum, molybdenum, and tungsten silicides for the photoelectrochemical oxidation of iodide. ${ }^{20}$ The longest lived photoanode for the photo-oxidation of iodide is a tungsten coated $\mathrm{p}^{+} \mathrm{n}$-Si photoanodes that remained active for over 187 days of continuous illumination $\left(>216000\right.$ C.cm $\left.{ }^{-2}\right) .{ }^{20}$ Interestingly, such silicide protection layers developed 20 years ago remain some of the longest lived photoelectrodes reported to date.

In this study, we investigate the photoelectrochemical activity and stability of two similar, but distinct protection schemes for silicon photocathodes, Scheme 1a and Scheme 1b. The first protection scheme $\left(\mathrm{Si}-2 \mathrm{IL}-\mathrm{MoS}_{2}\right)$ has two interlayers (IL) between the surface $\mathrm{MoS}_{2}$ and silicon composed of molybdenum silicide and molybdenum metal. The second protection scheme investigated has three IL (Si-3IL-MoS 2$)$ identified as molybdenum oxide, molybdenum silicide and silicon dioxide. The photocathodes are amongst the most stable precious metal free electrodes prepared to date, with over $1538 \mathrm{~h}$ of continuous and stable photoelectrochemical hydrogen evolution, ${ }^{21}$ and over $64000 \mathrm{C} \mathrm{cm}^{-2}$ of charge passed for the Si-3IL-MoS 2 protection scheme. These non-precious metal photoelectrodes also show an excellent onset potential, reaching $0.5 \mathrm{~mA} \mathrm{~cm}^{-2}$ at $+0.31 \mathrm{~V}$ vs. RHE. This serves as a promising protection scheme for active and stable photoelectrochemical water splitting.

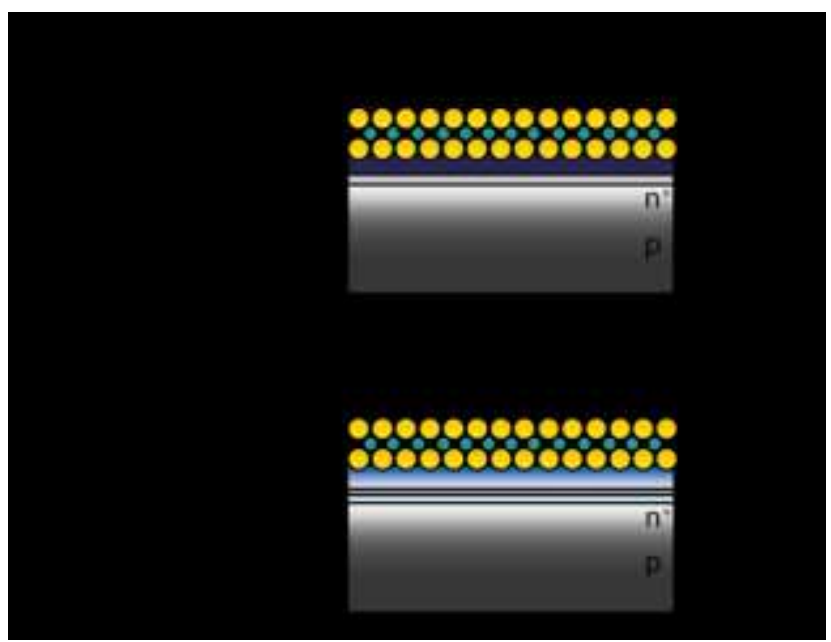

Scheme 1. Schematics detailing the catalyst and protection layers at the silicon interface in the synthesised (a) Si-2IL-MoS 2 and (b) Si-3IL-MoS 2 photocathodes. 


\section{Results and Discussions}

The Si-2IL-MoS 2 photocathode. The Si-2IL-MoS 2 photocathode was prepared following the method published in ref 15 and detailed in Scheme 1a. The protection scheme composition was confirmed (ref 15) by cross-sectional TEM and found to contain two interlayers (IL) between a surface $\mathrm{MoS}_{2}$ and the silicon substrate. The uppermost IL was a Mo metal layer. The second IL was identified as amorphous $\mathrm{Mo}_{\mathrm{x}} \mathrm{Si}$.

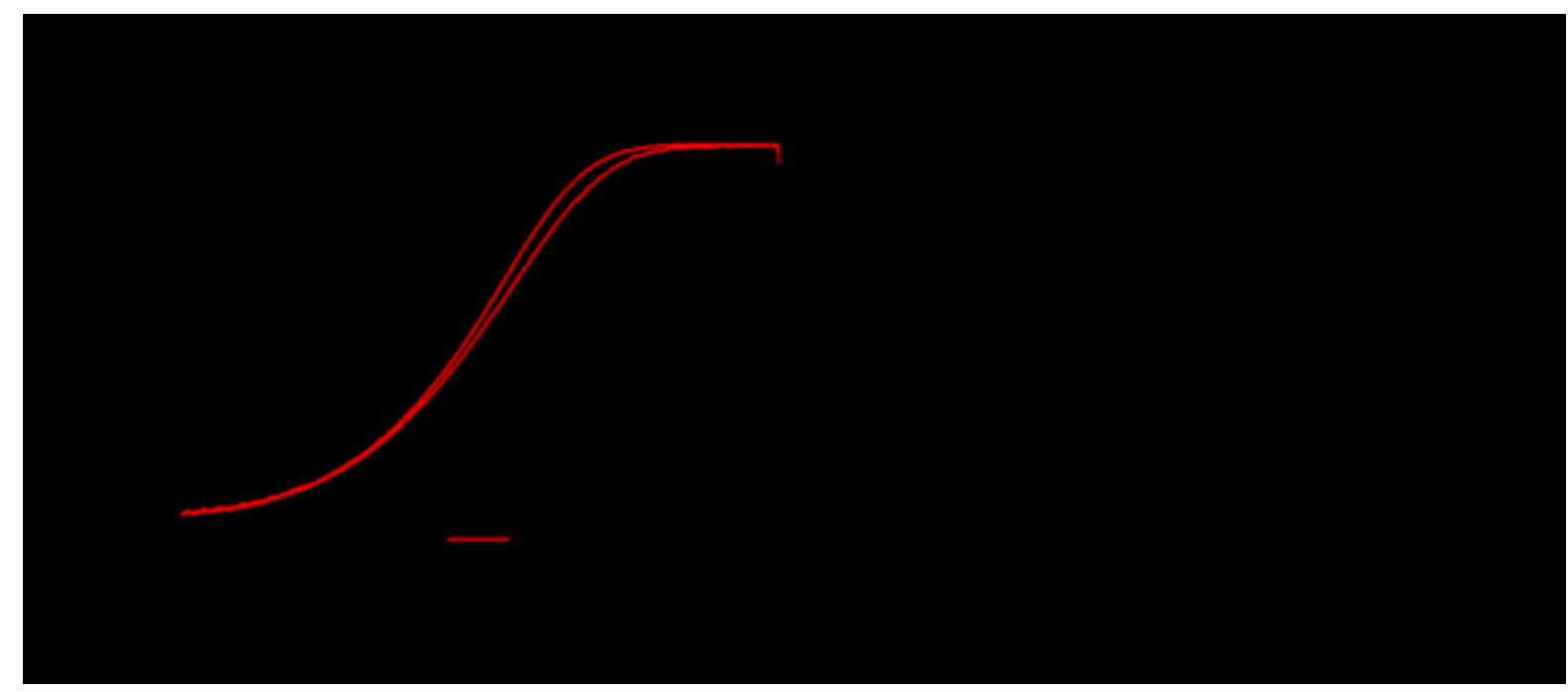

Figure 1. Photoelectrochemical stability measurements for the Si-2IL-MoS 2 photocathodes; Cyclic voltammograms, (a) were taken every 24 hours, here we show the CV taken on day 1 (black) and the last day of testing prior to failure (red). (b) Chronoampherometry measurements at $\mathrm{E}=0 \mathrm{~V}$ vs. RHE.

To probe the stability and performance of the prepared photocathodes, the photoelectrodes were continuously illuminated under approximately AM1.5 until catastrophic failure (as measured by loss in photocurrent). The current density was measured throughout testing while holding the electrode at $0 \mathrm{~V}$ vs. RHE. A cyclic voltammogram was recorded once every $24 \mathrm{~h}$ to access changes in the electrodes current-voltage characteristics. The onset potential of the $\mathrm{Si}-2 \mathrm{IL}-\mathrm{MoS}_{2}$ photocathode was recorded at $+0.28 \mathrm{~V}$ vs. RHE (defined as the potential required to reach $0.5 \mathrm{~mA} . \mathrm{cm}^{-2}$ ), in line with our previous work on similarly prepared photoelectrodes (Fig. 1 a). ${ }^{15}$ Three repeat electrodes were prepared and their initial photoelectrochemical performance is compared in Fig. S2a. The stability measurements were conducted for $100 \mathrm{~h}$ previously. ${ }^{15}$ Here, we extend the stability and find the photocathode to be stable for 24 days $(606 \mathrm{~h})$ of continuous illumination (Fig. $1 \mathrm{~b}$ ). The average photocurrent was $15.7 \mathrm{~mA} \mathrm{~cm}{ }^{-2}$ with $>34000 \mathrm{C} \mathrm{cm}^{-2}$ charge passed prior to failure. 
Over the duration of the PEC stability measurements the light limiting saturation photocurrent of the Si-2IL-MoS 2 photocathode increased (Fig. 1) from approximately -16.5 $\mathrm{mA} \mathrm{cm} \mathrm{cm}^{-2}$ to $-19.0 \mathrm{~mA} \mathrm{~cm}^{-2}$ (at $-0.3 \mathrm{~V}$ vs. RHE). We speculate that this is due to a combination of the dissolution of molybdenum, and/or roughening of the electrode surface over the 25 days of continuous testing, leading to a thinning of the protection/catalytic layers resulting in a reduction of the parasitic light absorption. In addition to the increased photocurrent at around $-0.3 \mathrm{~V}$ vs. RHE a slight increase in the onset potential was also measured for the photocathode. Specifically, the Si-2IL-MoS 2 photocathode increased from $+0.28 \mathrm{~V}$ to $+0.33 \mathrm{~V}$ vs. RHE. Increases in photoelectrode performance over the course of stability measurements have previously been observed for other $\mathrm{MoS}_{2}$ protected photocathodes and have been ascribed to the gradual exposure of additional $\mathrm{MoS}_{2}$ edge sites, ${ }^{15,18}$ which are known to be the active sites for HER. ${ }^{22}$ However, increasing the number of catalytic sites of the $\mathrm{MoS}_{2}$ catalyst should only increase reaction kinetics leading to an increase in the slope of the current-voltage curve and, perhaps its saturation photocurrent value. Therefore, we ascribe the change in onset potential to a surface chemical composition modification such as the exposure of underlying layers, such as molybdenum or molybdenum silicide. On the $25^{\text {th }}$ day of testing, failure of the Si-2IL-MoS 2 photocathode occurs during a chronoamperometry hold whereby the current drops from -16.4 $\mathrm{mA} \mathrm{cm}{ }^{-2}$ to $-1.9 \mathrm{~mA} \mathrm{~cm} \mathrm{~cm}^{-2}$ over approximately $4.5 \mathrm{~h}$. Complete failure (a reduction in photocurrent to $<-0.1 \mathrm{~mA} \mathrm{~cm}^{-2}$ ) occurs over a $24 \mathrm{~h}$ period.

Despite the overall excellent photoelectrochemical stability of the photocathode, some fluctuation in the photocurrent onset, saturation density and chronoampherometry was observed over the course of the stability tests (Fig. 1). The fluctuations in current density can be attributed to two distinct phenomena. Firstly, the smaller amplitude (up to $1 \mathrm{~mA} \mathrm{~cm}{ }^{-2}$ ), higher frequency noise which is attributed to the accumulation and removal of $\mathrm{H}_{2}$ bubbles at the electrode surface. The second distinct noise in the data consists of significantly larger spikes in the current density $\left(1-8 \mathrm{~mA} \mathrm{~cm}^{-2}\right)$ that occur approximately every $24 \mathrm{~h}$ which we speculate could be due to formation of $\mathrm{MoO}_{3}$ which is unstable at cathodic potentials in $0.5 \mathrm{M}$ sulfuric acid and/or contamination. Detailed discussion and explanation for the fluctuations is provided in the supporting information.

XPS characterisation was performed before and after photoelectrochemical experiments to identify the composition and chemical state of the two photocathodes (Fig. 2.). Peak fitting shows that the Mo $3 \mathrm{~d}$ region contains peaks associated with $\mathrm{Mo}(228.2$ and $231.6 \mathrm{eV})$ and $\mathrm{Mo}^{4+}$ (229.0 and $232.2 \mathrm{eV}$ ) only in addition to the $\mathrm{S} 2 \mathrm{~s}$ region $(226.2 \mathrm{eV})$. Quantification of the Mo 
$3 \mathrm{~d}$ region reveals $20 \%$ of the molybdenum is metallic, and $80 \%$ is Mo $(+4)$. In the silicon $2 \mathrm{p}$ region, no signal (within the detection limits) is detected. A doublet is observed in the sulfur $2 p$ region at approximately $163 \mathrm{eV}$. Post catastrophic failure, both elemental (or zero valent) molybdenum and sulfur are below the detection limits for the XPS. Silver contamination was detected at the surface of the failed electrode. Evidently, the protection layer has been completely removed from the surface leading to catastrophic failure of the device.

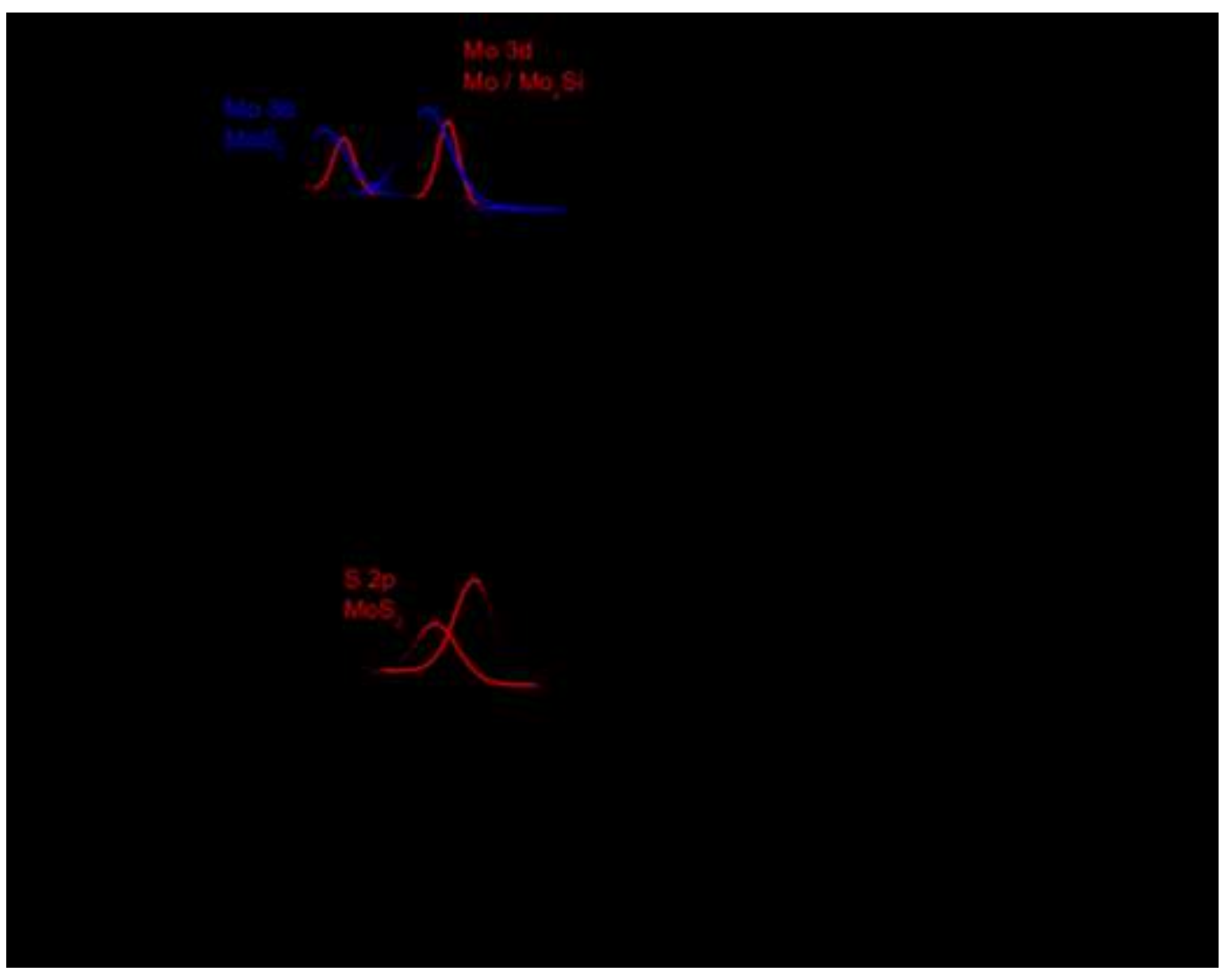

Figure 2. XPS data and fittings of the Si-2IL-MoS 2 photocathode for the (a) Mo 3d, (b) Si 2p and (c) $\mathrm{S} 2 \mathrm{p}$ regions. The as prepared photocathode spectra are shown in the upper plots, and post photoelectrochemical testing in the lower plots.

The Si-3IL-MoS 2 Photocathode. The synthesis of the Si-3IL-MoS 2 photocathode is presented in Scheme 1b. In brief, p-type silicon was $\mathrm{n}^{+}$doped, cleaned and coated with a $3.6 \mathrm{~nm}$ layer of molybdenum by sputtering. The electrodes were subsequently annealed in a $\mathrm{H}_{2}$ atmosphere at $550{ }^{\circ} \mathrm{C}(2 \mathrm{~h})$, followed by a second anneal step in $10 \% \mathrm{H}_{2} \mathrm{~S}$ in $\mathrm{H}_{2}$ at $250{ }^{\circ} \mathrm{C}(1 \mathrm{~h})$.

Cross sectional transmission electron microscope (TEM) images of the as prepared sample is shown in Fig. 3. evidencing the formation of a $\sim 3.7 \mathrm{~nm}$ silicon oxide $\left(\mathrm{SiO}_{2}\right)$ layer directly above the silicon, and a $\sim 10 \mathrm{~nm}$ layer of molybdenum/molybdenum oxide $\left(\mathrm{Mo} / \mathrm{MoO}_{\mathrm{x}}\right)$ above the $\mathrm{SiO}_{2}$. There is also evidence of an additional thin $(1-2 \mathrm{~nm})$ layer between the $\mathrm{MoO}_{\mathrm{x}}$ and 
$\mathrm{SiO}_{2}$ which is likely molybdenum silicide $\left(\mathrm{MoSi}_{\mathrm{x}}\right)$. Platinum is the uppermost layer, deposited during cross sectional TEM preparation as a protection layer for the FIB ion beam milling.

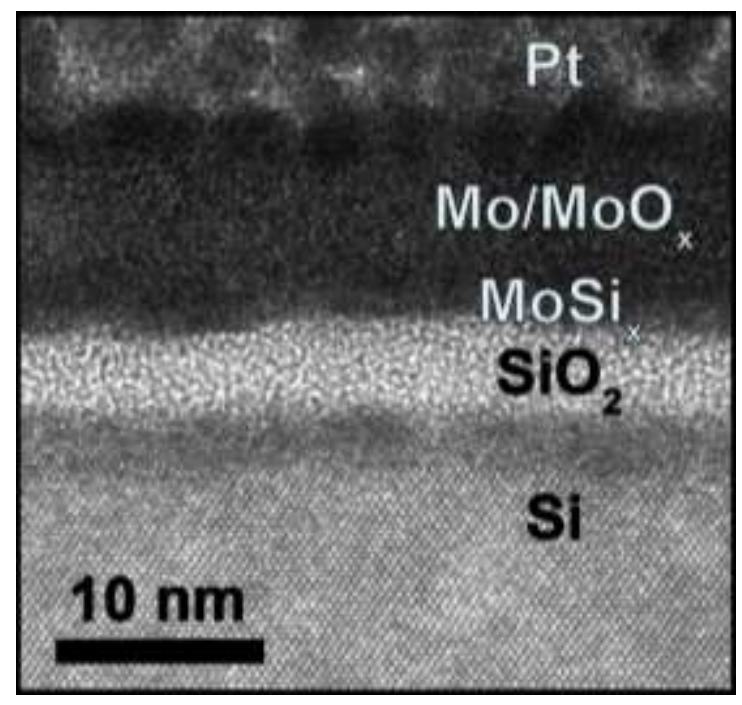

Figure 3. Transmission electron microgram (TEM) of the as prepared molybdenum protected Si-3IL$\mathrm{MoS}_{2}$ photocathode. Platinum is deposited during cross sectional TEM preparation as a protection layer for the FIB ion beam milling so is not present during the photoelectrochemical measurements.

The overall thickness of the Si-3IL-MoS 2 protection scheme $(\sim 14 \mathrm{~nm})$ is greater than the Si2IL-MoS 2 protection scheme. This is due to a thicker $\mathrm{MoO}_{\mathrm{x}}$ layer, in combination with an additional layer of $\mathrm{SiO}_{2}$. Interestingly, the distinct basal plane d spacing $(0.62 \mathrm{~nm})$ of $\mathrm{MoS}_{2}$ are absent in the Si-3IL-MoS 2 TEM (Fig. 3) indicating a non-continuous film of $\mathrm{MoS}_{2}$. The Si$3 \mathrm{IL}-\mathrm{MoS}_{2}$ photocathode synthesis requires a pre-reduction in a hydrogen atmosphere, which has been shown to limit the growth of $\mathrm{MoS}_{2},{ }^{23}$ however, XPS (Fig. 4) verifies the growth of $\mathrm{MoS}_{2}$ at the surface of the photocathode. 


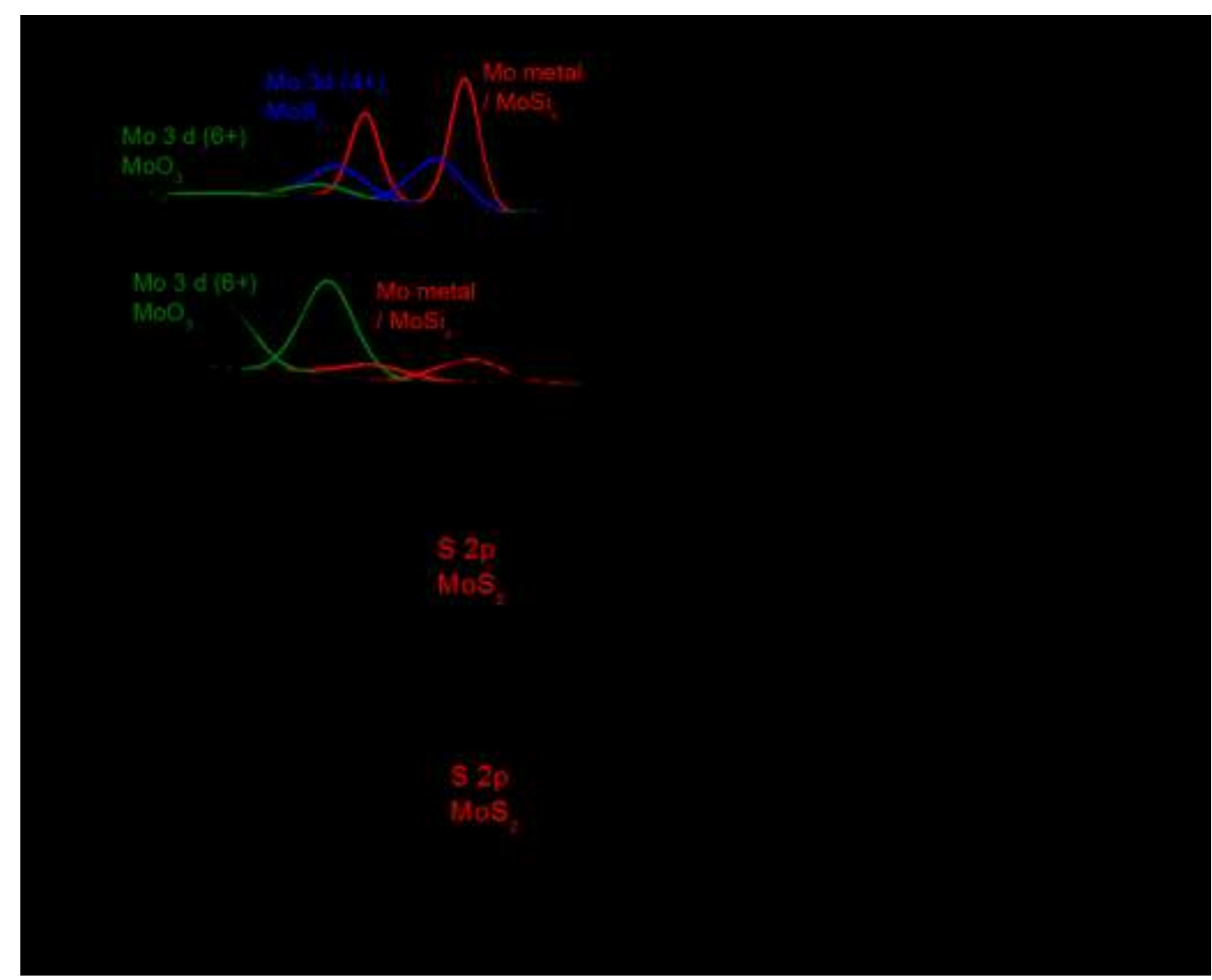

Figure 4. XPS data and fittings of the Si-3IL-MoS 2 photocathode for the (a) Mo 3d, (b) Si 2p and (c) $\mathrm{S} 2 \mathrm{p}$ regions. The as prepared photocathode spectra are shown in the upper plots, and post photoelectrochemical testing in the lower plots.

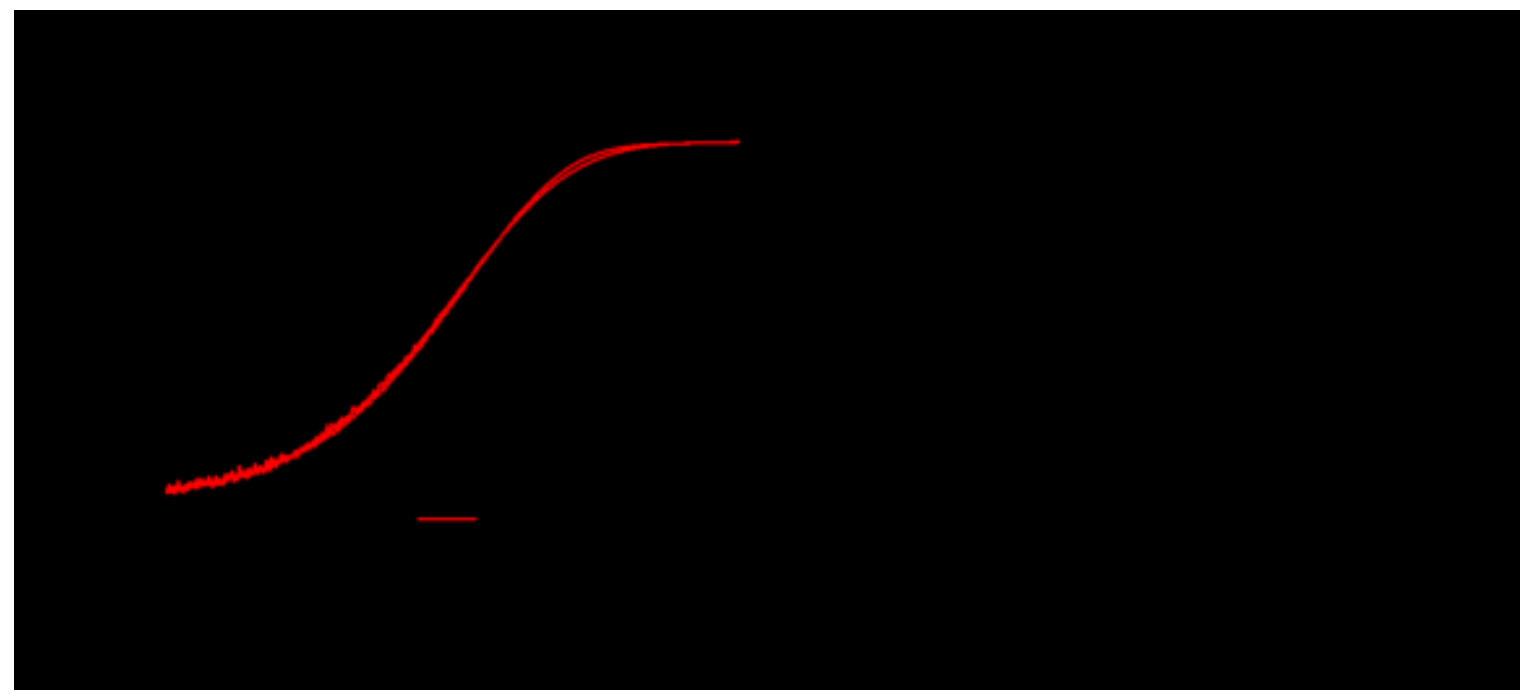

Figure 5. Photoelectrochemical stability measurements for the Si-3IL-MoS 2 photocathodes; Cyclic voltammograms, (a) were taken every 24 hours, here we show the CV taken on day 1 (black) and the last day of testing prior to failure (red). (b) Chronoampherometry measurements at $\mathrm{E}=0 \mathrm{~V}$ vs. RHE. 
The cyclic voltammograms (Fig. 5 a) reveal an excellent onset potential of $+0.31 \mathrm{~V}$ (defined here as the potential required to achieve $\left.-0.5 \mathrm{~mA} \mathrm{~cm}^{-2}\right)^{17}$ and achieves $-10 \mathrm{~mA} \mathrm{~cm}^{-2}$ at +0.09 V vs. RHE on both day 1 and day 62. Similar photoelectrochemical performance was recorded for repeat samples as shown in Fig. S2b. The electrodes were found to be active with an average saturation photocurrent density of $11.1 \mathrm{~mA} \mathrm{~cm}^{-2}$ for over 64 days $(1538 \mathrm{~h})$ under continuous illumination and PEC testing (Fig. 5 b), equivalent to 320 calendar days of $\mathrm{H}_{2}$ production under AM 1.5, sunny conditions with a solar capacity factor of $20 \%$. ${ }^{1,24}$ Bubble formation at the electrode surface was observed throughout the testing period passing $>64000$

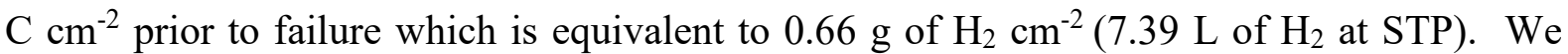
observe similar noise/fluctuations in the chronoampherometry measurements as in that recorded for the Si-2IL-MoS 2 photocathode (see supporting information for detailed explanations). For the Si-3IL-MoS 2 photocathode, the photocurrent increased from $-15.3 \mathrm{~mA}$ $\mathrm{cm}^{-2}$ to $-18.5 \mathrm{~mA} \mathrm{~cm}{ }^{-2}$ over the course of the durability measurement. Analogous to the Si2IL-MoS 2 photocathode, we speculate that this is due to a combination of the dissolution of molybdenum, and/or roughening of the electrode surface over the 64 days of continuous testing leading to a thinning of the protection/catalytic layers resulting in a reduction of the parasitic light absorption.

XPS characterisation was performed before and after photoelectrochemical experiments to identify the composition and chemical state of the Si-3IL-MoS 2 photocathode (Fig. 4.). XPS peak fitting of the freshly prepared photocathode shows that the Mo $3 \mathrm{~d}$ region contains peaks associated with metallic Mo (228.0 and $231.2 \mathrm{eV}) \mathrm{Mo}^{4+}(228.9$ and $232.1 \mathrm{eV})$ and $\mathrm{Mo}^{6+}(232.6$ and $235.8 \mathrm{eV})$ in addition to the $\mathrm{S} 2 \mathrm{~s}$ peak $(226 \mathrm{eV})$. Quantification of the relative areas of each molybdenum oxidation states reveal the electrode contains 55\% Mo and/or $\mathrm{MoSi}_{\mathrm{x}}, 35 \%$ $\mathrm{MoS}_{2}$ and/or $\mathrm{MoO}_{2}, 10 \% \mathrm{MoO}_{3}$. The "as prepared" photocathode silicon $2 \mathrm{p}$ signal has a rather high silicon oxide signal. This can be accredited to the formation of a silicon oxide layer, which is approximately $3.7 \mathrm{~nm}$ thick according to the cross sectional TEM (Fig. 3). ${ }^{25}$ Sulfur species are also detected by XPS in the "as prepared" electrode. Prior to PEC testing the XPS peaks at $226 \mathrm{eV}$ and $162 \mathrm{eV}$ were assigned to $\mathrm{S}^{2-} 2 \mathrm{~s}$ and $2 \mathrm{p}_{3 / 2}$ respectively. ${ }^{15}$

The failure of the Si-3IL-MoS 2 photocathode occurs after $1538 \mathrm{~h}$ of continuous PEC testing. The failure is catastrophic and occurs during a chronoampherometry measurement where the photocurrent drops abruptly from $\sim 10 \mathrm{~mA} \mathrm{~cm}^{-2}$ to $-0.2 \mathrm{~mA} \mathrm{~cm}{ }^{-2}$ over $5 \mathrm{~h}$. After the failure, XPS characterisation reveals a drastic transformation in the chemical oxidation states of the elements present at the surface of the photocathode. Similarly to the Si-2IL-MoS 2 electrode, 
silver contamination was detected at the surface of the failed electrode. Significantly, the proportion of oxidized molybdenum $(\mathrm{Mo}(+6))$ increased from $10 \%$ to $75 \%$. Post failure, $\mathrm{S}^{2-}$ can still be observed in the sulfur $2 \mathrm{p}$ region indicating that some $\mathrm{MoS}_{2}$ likely is still present. However, the decrease in $2 \mathrm{Mo}^{4+}$ relative to $\mathrm{Mo}^{6+}$ indicates that some of the $\mathrm{MoO}_{2}$ and $\mathrm{MoS}_{2}$ has been removed from the electrode surface. The presence of an additional S $2 p$ doublet at $\sim 168.6 \mathrm{eV}$ post failure can be assigned as the oxidized sulfur species $\mathrm{SO}_{4}{ }^{2-}$ which is attributed to the usage of sulfuric acid as electrolyte throughout the PEC testing. The Si $2 p$ signal postfailure consists of both oxidised $\mathrm{SiO}_{2}(103.2 \mathrm{eV})$ and either elemental or silicide $\mathrm{Si}(99.8 \mathrm{eV})$, difficult to discern due to the small $(0.2 \mathrm{eV})$ difference between the their binding energies. The XPS signal for $\mathrm{Si} / \mathrm{MoSi}_{\mathrm{x}}$ is significantly enhanced post PEC testing suggesting that the molybdenum based protection layer is damaged, and thinner/discontinuous in places.

To further probe the failure mechanism of the Si-3IL-MoS 2 photocathode, scanning electron microscopy (SEM) and cross sectional TEM were used. SEM reveals a highly-roughened surface with both pits $(10-40 \mathrm{~nm}$ ) and agglomerates (up to $100 \mathrm{~nm}$ ) scattered across the surface (Fig. 6 a). The cross sectional TEM images of the same sample (Fig. 6 b and Fig. S1) reveal significant roughening across the surface with pits up to $30 \mathrm{~nm}$ deep, as well as the addition of particles $(10-20 \mathrm{~nm})$. Behind the cavity, silicon lattice planes remain visible suggesting the cavity is only a few $\mathrm{nm}$ wide. Scanning TEM energy dispersive $\mathrm{x}$-ray spectroscopy (STEM-EDS) elemental maps (Fig. 6.c-f) show that the pits extend through the protective molybdenum based layers, into the silicon and that silicon is etched away. The particles that decorate the surface were found to contain predominantly molybdenum, and in some cases silver (contaminant). Discussion regarding the origin of the contaminant is provided in the supporting information. In light of the cross sectional TEM (Fig. 6 b) whereby large pits and a broken protection layer is observed we speculate that such morphological changes are likely the eventual cause of electrode failure. Given that these failures occur during chronoampherometry testing we conclude that failure is not as a direct consequence of the cyclic voltammetry sweeps. 


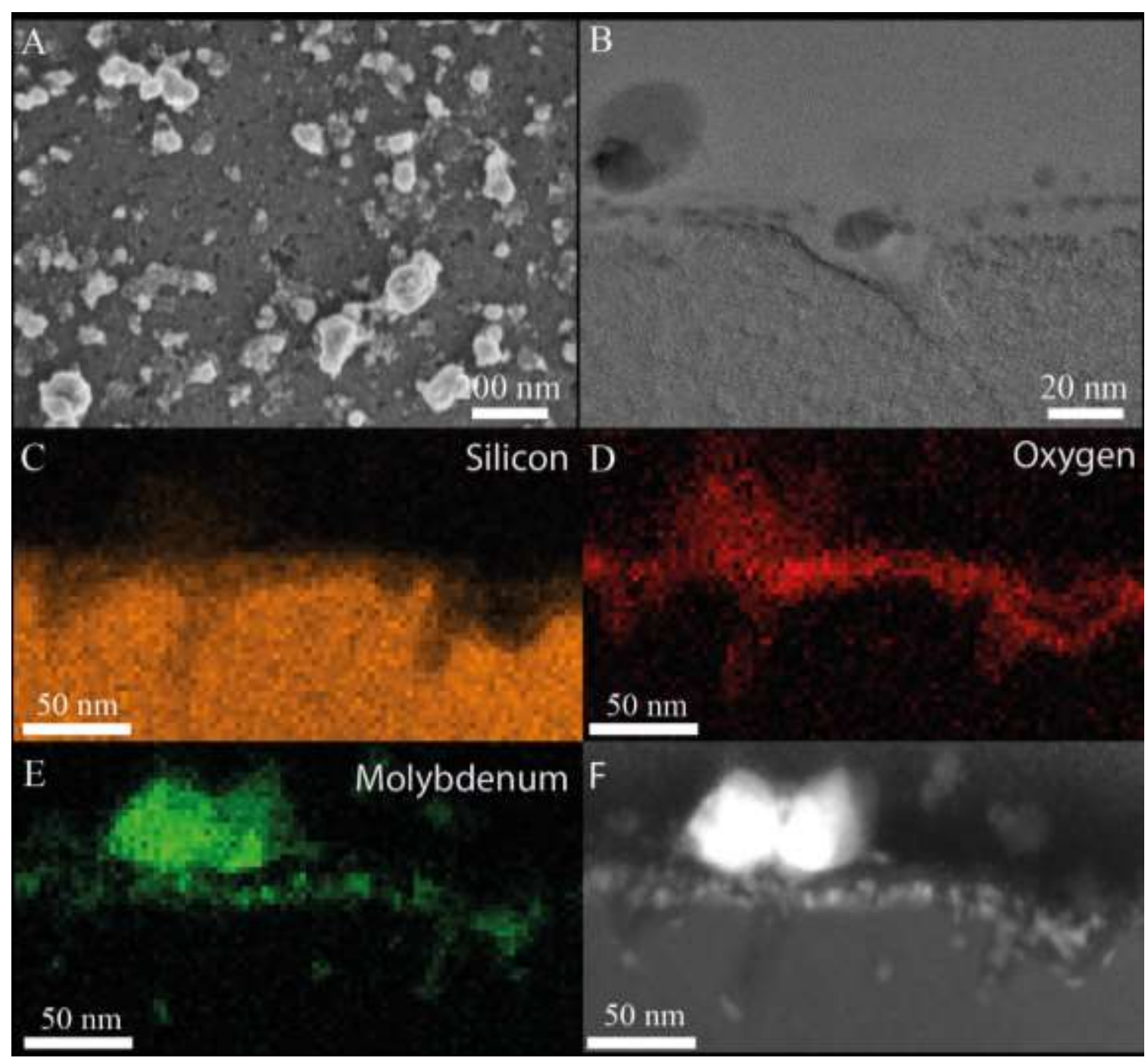

Figure 6. (A) Scanning electron micrograph (SEM) and (B) cross-sectional transmission electron micrograph (TEM) of the Si-3IL-MoS 2 photocathode post failure. Both pits and agglomerates are clearly visible at the surface of the electrode. STEMEDS mapping of silicon (C), oxygen (D) and molybdenum (E) of the sample after failure (64 days of testing). (F) The STEM micrograph of the same region is also shown.

Table 1 summarises the photoelectrochemical properties and durability of the two protection schemes investigated in this work. We speculate that the overall thickness of the Si-3IL-MoS 2 protection scheme, relative to that of the Si-2IL-MoS 2 , in combination with both the $\sim 3.7 \mathrm{~nm}$ $\mathrm{SiO}_{2}$ and $1-2 \mathrm{~nm} \mathrm{MoSi}$ layers provide additional chemical stability and thus contribute to the longevity of the devices enhancing the lifetime both with regards to time and total charge passed. We highlight the importance of future studies in this field that can uncover the specific role of individual layers (both chemical composition and thickness). Through a series of systematically designed and synthesised silicon photocathodes we plan to uncover the specific role of the individual layers $\left(\mathrm{MoO}_{\mathrm{x}} / \mathrm{SiO}_{2} / \mathrm{MoSi}_{\mathrm{x}}\right)$ in future experiments. Impurities at the 
electrode surface are one of the many possible contributing factors to the failure of photoelectrodes. Impurities can be introduced into the system during various stages of the synthesis/testing, e.g. sputter deposition, annealing in the tube furnace, from electrolyte, water and the reference electrode. Furthermore, prior to deployment of industrial scale photoelectrochemical plants investigation of such sources and roles of impurities on device performance and stability will be of great importance.

Table 1. Summary of photoelectrochemical performance of the two photocathodes.

\begin{tabular}{lccccc}
\hline Photocathode & $\begin{array}{c}\text { Onset } \\
\text { Potential (V } \\
\text { vs. RHE) }\end{array}$ & $\begin{array}{c}\text { Photocurrent } \\
\text { Saturation (mA } \\
\left.\mathbf{c m}^{-2}\right)\end{array}$ & $\begin{array}{c}\text { Stability } \\
\text { (h) }\end{array}$ & $\begin{array}{c}\text { Charge } \\
\text { passed (C } \\
\mathbf{c m}^{-2} \text { ) }\end{array}$ & $\begin{array}{c}\text { Volume } \\
\text { of } \mathbf{H}_{\mathbf{2}} \\
\text { (STP L) }\end{array}$ \\
\hline Si-2IL-MoS 2 & +0.28 & $16.5-19.0$ & 606 & $>34000$ & 3.98 \\
Si-3IL-MoS & +0.31 & $15.3-18.5$ & 1638 & $>64000$ & 7.39 \\
\hline
\end{tabular}

\section{Conclusion}

In conclusion, we report over $1500 \mathrm{~h}$ stability and over $64000 \mathrm{C} \mathrm{cm}^{-2}$ charge passed for a precious metal free molybdenum sulfide catalysed and molybdenum silicide protected silicon photocathode. Based on the high activity and durability of the molybdenum disulfide catalyst, we maintain an excellent onset potential for $>62$ days of continuous hydrogen production. Our investigation of two similar, but distinct protection schemes on silicon photocathodes provide evidence that molybdenum disulfide coupled to molybdenum oxide, molybdenum silicide layers and silicon dioxide creates an extremely effective barrier to corrosion. Catastrophic electrode failure reveals that some molybdenum remains present though over $75 \%$ of the molybdenum is oxidised. Microscopy of the electrode post-mortem unveils a surface exhibiting pits and agglomerates/particles. Our findings demonstrate significant photoelectrode longevity and provide insights into degradation mechanisms that can enable strategies for future synthesis of highly durable PEC water splitting electrodes. 


\section{Methods}

Synthesis of $\mathbf{n}^{+} \mathbf{p}-\mathbf{S i}-\mathbf{M o}$. For both photocathode syntheses, p-type (0.1-0.9 ohm) wafers (WRS) were cleaned (standard SC1 $\left(5: 1: 1 \mathrm{H}_{2} \mathrm{O}: \mathrm{H}_{2} \mathrm{O}_{2}: \mathrm{NH}_{4} \mathrm{OH}\right.$ at $50{ }^{\circ} \mathrm{C}$ for 10 minutes), $\mathrm{HF}$ for $30 \mathrm{~s}$, and then $\mathrm{SC} 2\left(\mathrm{H}_{2} \mathrm{O}: \mathrm{H}_{2} \mathrm{O}_{2}: \mathrm{HCl}\right.$ at $50{ }^{\circ} \mathrm{C}$ for 10 minutes $)$ etches $)$ and doped with $\mathrm{POCl}_{3}$ in a tube furnace at $900^{\circ} \mathrm{C}$ for 10 mins. Following a further standard wafer clean (SC1 and SC2) and $\mathrm{SiO}_{2} \mathrm{BOE}$ etch, molybdenum metal $(3.6 \mathrm{~nm})$ was then sputtered onto the wafer with $<10$ min between the $\mathrm{SiO}_{2}$ etch and pump down in the sputtering system, thus minimising the regrowth of native $\mathrm{SiO}_{2}$. Post Mo sputtering, the sample was cleaved into approximately $0.2 \mathrm{~cm}^{2}$ sized pieces which were subsequently treated as described below.

Synthesis of the Si-2IL-MoS 2 Photocathode. The Si-2IL-MoS 2 photocathode was prepared following the method published in Ref 15 and detailed in Scheme 1a. In brief, the $\mathrm{n}^{+} \mathrm{p}-\mathrm{Si}$-Mo wafer was sulfidized in an $\mathrm{H}_{2} \mathrm{~S}$ environment at $250{ }^{\circ} \mathrm{C}$ for 45 mins.

Synthesis of the Si-3IL-MoS2 Photocathode. The synthesis of the Si-3IL-MoS 2 photocathode is presented in Scheme 1b. In brief, the prepared $n^{+}$p-Si-Mo were annealed in a $\mathrm{H}_{2}$ atmosphere at $550{ }^{\circ} \mathrm{C}$ (ramp rate 5 degree/min, $2 \mathrm{~h}$ dwell), followed by a second anneal step in $10 \% \mathrm{H}_{2} \mathrm{~S}$ in $\mathrm{H}_{2}$ at $250{ }^{\circ} \mathrm{C}$ (ramp rate 5 degree/min, $1 \mathrm{~h}$ dwell). $99.999 \%$ UHP (ultra high purity) hydrogen gas was used for all the syntheses plumbed into the tube furnace using swage lock stainless steel pipping.

Electrode Mounting. Electrical back contacts were made to the photocathode by diamond scribing InGa eutectic onto the surface, followed by a thin layer of carbon paint (Ted Pella, DAG-T-502) and finally, an insulated conductive wire. The back side of the electrode was fully encapsulated/isolated from electrolyte with two layers of Loctite ${ }^{\circledR}$ E-120 hydrosol epoxy. A third layer of Loctite ${ }^{\circledR}$ EA 9462 epoxy was subsequently applied and left for $24 \mathrm{~h}$ drying prior to PEC testing. The total illuminated electrode surface area was $0.24 \mathrm{~cm}^{2}$.

Photoelectrochemical Measurements. To probe the stability of the prepared photocathodes, the electrodes were continuously illuminated under approximately AM1.5 until catastrophic failure (as measured by a loss in photocurrent). The current density was continuously measured while holding the electrode at $0 \mathrm{~V}$ vs. RHE, with the exception of a cyclic voltammogram recorded once every $24 \mathrm{~h}$. Photoelectrochemical (PEC) testing was conducted in custom designed H-cells with a quartz window and in a three electrode configuration. All cell components (cell, gas dispersion tube, magnetic stir bar, quartz windows etc) were cleaned with aqua regia prior to PEC measurements. $0.5 \mathrm{M}$ sulfuric acid electrolyte $(99.9 \%$ purity, 
Sigma Aldrich) with an $\mathrm{H}_{2}$ purge and continuous stirring was used throughout all testing. A mercury/mercury sulfate reference electrode was used as a reference electrode and an iridium wire as a counter electrode which was separated from the photocathode electrode by a Nafion membrane. The reference electrode was calibrated with two Pt wires in $\mathrm{H}_{2} \mathrm{SO}_{4}$ before and after PEC testing to confirm stability over the 64 days of stability testing. The sample was illumined with an Abet Solar Simulator (model number 11002) xenon lamp. The incident illumination was calibrated to match AM1.5 solar spectrum. Given the longevity of the PEC testing (64 days), the light source was calibrated both before and after PEC testing using an Ocean Optics Jaz EL 200-XR1 spectrometer and the CV data adjusted for the measured loss in solar intensity.

Physical Characterisation. XPS analysis was performed with a Phi Versaprobe 1. SEM microscopy was made with FEI Magellan 400 XHR Scanning Electron Microscope (SEM). Two thin lamella samples were prepared using focused ion beam (FIB, FEI Helios nanolab 600i) lift-out technique to perform cross-section TEM imaging. Samples were thinned by $30 \mathrm{kV}$ Ga ion beam and final cleaning process was done at $3 \mathrm{kV}$ accelerating voltage to polish of ion beam induced amorphous materials. Surface roughness and elemental distribution was analysed by high resolution TEM images and scanning TEM energy dispersive $\mathrm{x}$-ray spectroscopy (STEM-EDS) operated at 80kV (TEM, FEI Titan environmental TEM 80-300).

\section{Supporting Information}

Additional discussion regarding the stability data, as well as HRTEM of the failed Si-3IL-MoS 2 is provided in the supporting information. This material is available free of charge via the Internet at http://pubs.acs.org.

\section{Author Information}

\section{Corresponding Author}

*Email: Jaramillo@stanford.edu 


\section{Acknowledgment}

This paper presents results from an NSF project (award number CBET-1433442) competitively-selected under the solicitation "NSF 14-15: NSF/DOE Partnership on Advanced Frontiers in Renewable Hydrogen Fuel Production via Solar Water Splitting Technologies”, which was co-sponsored by the National Science Foundation, Division of Chemical, Bioengineering, Environmental, and Transport Systems (CBET), and the U.S. Department of Energy, Office of Energy Efficiency and Renewable Energy, Fuel Cell Technologies Office. T.R.H. acknowledges support from the National Science Foundation Graduate Research Fellowship Program. Part of this work (XPS and SEM data collection) was performed at the Stanford Nano Shared Facilities (SNSF), supported by the National Science Foundation under award ECCS-1542152.

\section{References}

(1) Shaner, M. R.; Atwater, H. A.; Lewis, N. S.; McFarland, E. W. A Comparative Technoeconomic Analysis of Renewable Hydrogen Production Using Solar Energy. Energy Environ. Sci. 2016, 9 (7), 2354-2371.

(2) Walter, M. G.; Warren, E. L.; McKone, J. R.; Boettcher, S. W.; Mi, Q. X.; Santori, E. A.; Lewis, N. S. Solar Water Splitting Cells. Chem. Rev. 2010, 110, 6446-6473.

(3) McKone, J. R.; Lewis, N. S.; Gray, H. B. Will Solar-Driven Water-Splitting Devices See the Light of Day? Chem. Mater. 2014, 26 (1), 407-414.

(4) Seitz, L. C.; Chen, Z.; Forman, A. J.; Pinaud, B. A.; Benck, J. D.; Jaramillo, T. F. Modeling Practical Performance Limits of Photoelectrochemical Water Splitting Based on the Current State of Materials Research. ChemSusChem 2014, 7 (5), 1372-1385.

(5) Hu, S.; Lewis, N. S.; Ager, J. W.; Yang, J.; McKone, J. R.; Strandwitz, N. C. Thin-Film Materials for the Protection of Semiconducting Photoelectrodes in Solar-Fuel Generators. J. Phys. Chem. C 2015, 119 (43), 24201-24228.

(6) Gronet, C. M.; Lewis, N. S. Design of a 13\% Efficient N-GaAs1|[minus]|xPx Semiconductor-liquid Junction Solar Cell. Nature 1982, 300 (5894), 733-735.

(7) Gronet, C. M.; Lewis, N. S.; Cogan, G.; Gibbons, J. N-Type Silicon Photoelectrochemistry in Methanol: Design of a 10.1\% Efficient Semiconductor/Liquid Junction Solar Cell. Proc. Natl. Acad. Sci. U. S. A. 1983, 80 (4), 1152-1156.

(8) Bansal, A.; Lewis, N. S. Stabilization of Si Photoanodes in Aqueous Electrolytes through Surface Alkylation. J. Phys. Chem. B 1998, 102 (21), 4058-4060.

(9) Maier, C. U.; Specht, M.; Bilger, G. Hydrogen Evolution on Platinum-Coated P-Silicon Photocathodes. Int. J. Hydrog. Energy 1996, 21 (10), 859-864.

(10) Paracchino, A.; Laporte, V.; Sivula, K.; Grätzel, M.; Thimsen, E. Highly Active Oxide Photocathode for Photoelectrochemical Water Reduction. Nat. Mater. 2011, 10 (6), 456-461. 
(11) Esposito, D. V.; Levin, I.; Moffat, T. P.; Talin, A. A. H2 Evolution at Si-Based Metalinsulator-semiconductor Photoelectrodes Enhanced by Inversion Channel Charge Collection and H Spillover. Nat. Mater. 2013, 12 (6), 562-568.

(12) Scheuermann, A. G.; Lawrence, J. P.; Kemp, K. W.; Ito, T.; Walsh, A.; Chidsey, C. E. D.; Hurley, P. K.; Mclntyre, P. C. Design Principles for Maximizing Photovoltage in MetalOxide-Protected Water-Splitting Photoanodes. Nat. Mater. 2016, 15, 99-105.

(13) Cabán-Acevedo, M.; Stone, M. L.; Schmidt, J. R.; Thomas, J. G.; Ding, Q.; Chang, H.-C.; Tsai, M.-L.; He, J.-H.; Jin, S. Efficient Hydrogen Evolution Catalysis Using Ternary PyriteType Cobalt Phosphosulphide. Nat. Mater. 2015, 14 (12), 1245-1251.

(14) Hellstern, T. R.; Benck, J. D.; Kibsgaard, J.; Hahn, C.; Jaramillo, T. F. Engineering Cobalt Phosphide (CoP) Thin Film Catalysts for Enhanced Hydrogen Evolution Activity on Silicon Photocathodes. Adv. Energy Mater. 2016, 6 (4), 1501758.

(15) Benck, J. D.; Lee, S. C.; Fong, K. D.; Kibsgaard, J.; Sinclair, R.; Jaramillo, T. F. Designing Active and Stable Silicon Photocathodes for Solar Hydrogen Production Using Molybdenum Sulfide Nanomaterials. Adv. Energy Mater. 2014, 4 (18), 1400739.

(16) Laursen, A. B.; Pedersen, T.; Malacrida, P.; Seger, B.; Hansen, O.; Vesborg, P. C. K.; Chorkendorff, I. MoS2-an Integrated Protective and Active Layer on N+p-Si for Solar H2 Evolution. Phys. Chem. Chem. Phys. 2013, 15 (46), 20000-20004.

(17) Benck, J. D.; Hellstern, T. R.; Kibsgaard, J.; Chakthranont, P.; Jaramillo, T. F. Catalyzing the Hydrogen Evolution Reaction (HER) with Molybdenum Sulfide Nanomaterials. ACS Catal. 2014, 4 (11), 3957-3971.

(18) Britto, R. J.; Benck, J. D.; Young, J. L.; Hahn, C.; Deutsch, T. G.; Jaramillo, T. F. Molybdenum Disulfide as a Protection Layer and Catalyst for Gallium Indium Phosphide Solar Water Splitting Photocathodes. J. Phys. Chem. Lett. 2016, 7 (11), 2044-2049.

(19) Ijdiyaou, Y.; Azizan, M.; Ameziane, E. L.; Brunel, M.; Nguyen Tan, T. A. On the Formation of Molybdenum Silicides in Mo-Si Multilayers: The Effect of Mo Thickness and Annealing Temperature. Appl. Surf. Sci. 1992, 55 (2), 165-171.

(20) Nakato, Y.; Iwakabe, Y.; Hiramoto, M.; Tsubomura, H. Tungsten- or MolybdenumCoated P-n Junction Silicon Electrodes for Efficient and Stable Photoelectrochemical Solar Energy Conversion. J. Electrochem. Soc. 1986, 133 (5), 900-904.

(21) Bae, D.; Pedersen, T.; Seger, B.; Iandolo, B.; Hansen, O.; Vesborg, P. C. K.; Chorkendorff, I. Carrier-Selective P- and N-Contacts for Efficient and Stable Photocatalytic Water Reduction. Catal. Today 2017, 290, 59-64.

(22) Jaramillo, T. F.; Jørgensen, K. P.; Bonde, J.; Nielsen, J. H.; Horch, S.; Chorkendorff, I. Identification of Active Edge Sites for Electrochemical H2 Evolution from MoS2 Nanocatalysts. Science 2007, 317 (5834), 100-102.

(23) Massoth, F. E. Studies of Molybdena-Alumina Catalysts. J. Catal. 1975, 36 (2), 164-184.

(24) U.S. Energy Information Administration. Capacity Factors for Utility Scale Generators Not Primarily Using Fossil Fuels; 2008.

(25) The Oxidation of Silicides on Silicon. In The Physics and Chemistry of SiO2 and the SiSiO2 Interface; Helms, C. R., Deal, B. E., Eds.; Springer US, 1988; pp 85-94. 
Table of Contents Image

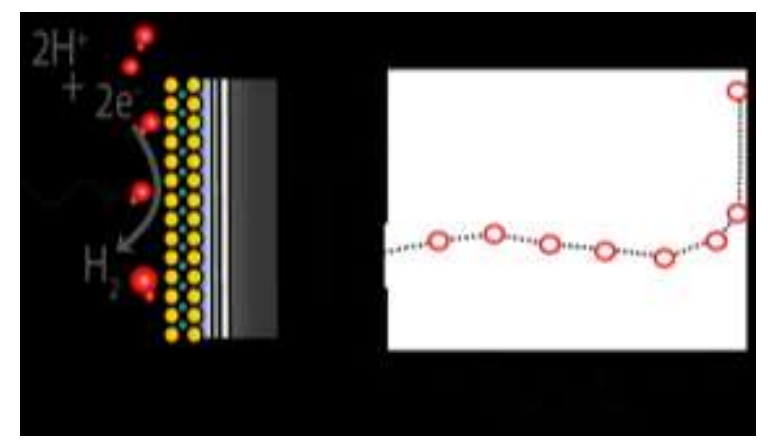

